RESEARCH ARTICLE

\title{
Family-Centered Care - A Tool to Decrease Malnutrition among Children in Vietnam
}

\section{Anna Hagström, Hedvig Florén and Kristina Rosengren*}

Sahlgrenska Academy, Institute of Health and Care Sciences, University of Gothenburg, Sweden

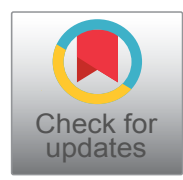

*Corresponding author: Kristina Rosengren, $P h D, R N$, Associate Professor, Sahlgrenska Academy, Institute of Health and Care Sciences, University of Gothenburg, PO Box 457, SE 40530 Gothenburg, Sweden, Tel: +46-31-786-6959, ORCID iD: 0000-0002-3221-2062

\begin{abstract}
Background: Malnutrition is a global problem with almost 2.4 billion suffering people around the world.

Aim: The aim of this study was to describe nursing students' experiences of malnutrition among children within hospital in Vietnam.

Method: Data collection was gained by seven semistructured interviews with nursing students in their last year at the Advanced Nursing Program at Hanoi Medical University, Vietnam. Data was analyzed through a manifest qualitative content analysis.

Result: One category was found; Support through familycentered care, which includes two subcategories; Supporting healthy eating habits within the family and Managing limited resources, which describe nursing student's experiences of malnutrition among children in Vietnam.

Conclusion: Nurses are resources within healthcare to identifying risk factors regarding malnutrition such as financial vulnerability, eating habits and access to healthcare. However this requires improvements regarding nursing education (malnutrition, family-centered care) as well as focus on nursing tasks (prevention, follow-up) in primary and hospital care by increased number of nurses.
\end{abstract}

\section{Keywords}

Children, Malnutrition, Nursing students, Suffering, Qualitative content analysis, Vietnam

\section{Introduction}

World Health Organization, WHO [1] highlight that malnutrition is a worldwide problem with nearly 2.4 billion affected people due to imbalance in nutrition and energy intake. In Vietnam, $14.1 \%$ of children under five years are underweighted, $24.6 \%$ of them suffered from "stunting" (reduced median length to age), and $6.4 \%$ had "wasting" (reduced median weight to the length). Though nurses has an important role to prevent malnutrition and/or alleviate suffering, current study aims to broaden knowledge regarding malnutrition among children by adding forthcoming nurses (nursing student's) perspective.

\section{Background}

Malnutrition is a worldwide problem [1] due to underweighted (lack of food, beverages) as well as over weighted (cheap food, beverages with fat, salt, sugar). United Nations Millennium Development Goal 1 declare to fight poverty in which hunger and malnutrition are included [2]. Malnutrition among children is described in relation to weight and length. "Wasting" are described as a child's median weight deviates to length with two standard deviations, stunting are median length deviates with two standard deviations in relation to age $[3,4]$. Huong, et al. [5] described that $13.9 \%$ of all Vietnam children in hospital suffered from "stunting" and $19.0 \%$ of "wasting". Moreover, Truong Quang Dat, et al. [6] show downward trend regarding prevalence of malnutrition from $17.5 \%$ in 2010 to $14.1 \%$ in 2015 with expectancy to decline even more. The stunting malnutrition prevalence has also declined from $29.3 \%$ to $24.2 \%$ (2010-2015). While underweight has dropped rapidly (>60\%) compared to 1990 , the obesity prevalence in children (< age 5) is growing rapidly [6].

Moreover, malnutrition is one of the most common

Citation: Hagström A, Florén H, Rosengren K (2019) Family-Centered Care - A Tool to Decrease Malnutrition among Children in Vietnam. Int Arch Nurs Health Care 5:116. doi.org/10.23937/24695823/1510116

Accepted: January 22, 2019: Published: January 24, 2019

Copyright: (c) 2019 Hagström A, et al. This is an open-access article distributed under the terms of the Creative Commons Attribution License, which permits unrestricted use, distribution, and reproduction in any medium, provided the original author and source are credited. 
causes of mortality (50\%) among young children $(<$ five year) due to infections and prolonged recovery after ill-health [7]. Research [8] show that malnutrition during childhood affects the function of growth though concentration of stress hormone cortisol increase, which inhibits effect of several hormones as igf-1, $\mathrm{GH}$. In the short term, hormones are survival strategy but cause risk of impaired cognitive ability and why malnutrition trigger adaptive physiological mechanisms to prioritize brain development instead of body growth [1]. In addition, nutritional status during pregnancy also impact brain and body growth [9].

Jefferies, et al. [10] stress that nurse's task is to support well-compound meals together with the family, why nurses need knowledge and accessibility to identify risk of malnutrition due to swallowing difficulties or eating disorders [11]. Nurses use screening instruments to identify malnutrition [12]. Most common tool to measure malnutrition is Body Mass Index, BMI [13] that indicate units to $\mathrm{kg} / \mathrm{m}^{2}$, underweight $(<18.5)$ which contribute to cognitive problems as well as overweight $(>25)$ that influence non-communicable diseases such as diabetes and cardiovascular diseases [1]. BMI for children and teens is age-(2-18 year) and sex-specific and is often referred to as BMI-for-age, where underweight is described on the second centile or below, overweight is described as 91 centile or above. Centile show children's BMI compare to results from national surveys, for example, a girl in 80 centile is heavier than 80 out of 100 girls in her age [14]. Underand over weight in low and middle-income countries create double burden [15], suffering (individual/family) as well as consumption of healthcare (society). III-health and mortality due to malnutrition results in loss of human capital as productivity regarding country's Gross Domestic Product, GDP [16].

Increased socio-economic reforms in the 90's in Vietnam resulted in significant reduction of poverty and improved health status within the population [17]. For example Le Nguyen, et al. [18] study showed lower proportion of underweight among younger children compared to children of school age, which were related to breast feeding as well as sustainable environment with available food and clean water. Therefore, malnutrition among Vietnamese children < five years had decreased [19], from $64.1 \%$ in 1984 to $23.3 \%$ in 2010 [4], but minority populations and people with poor socioeconomic status (families with $>3$ children) are still at risk, especially in rural areas [20].

According to the International Council of Nursing, ICN [21], improve well-being is one of nurse's four main responsibilities in nursing, suffering regarding malnutrition is a major nursing task. According to Nordman, et al. [22], suffering could be divides into three areas; ill-health that cause body pain and mental suffering, suffering caused by care or lack of care, and finally suffering caused by life-threatening situations.
Suffering are described different, for example, a healthy child experience vaccination (pinprick) with crying (internal factors). However, child suffering during treatment (ill health) focusing on external factors as medical intervention to receive attention from their parents to compensate and create harmony regarding emotional development [23]. Moreover, research [24] regarding nursing students' experience of suffering in healthcare show increased awareness regarding their own vulnerability.

Family-centered care, FCC are described as philosophy of care, a framework for pediatric nurses to care for infants and children to support and promote physical, emotional and psychological health in the context of the family, for example fight malnutrition. FCC are built upon a ubiquitous team in pediatric health facilities to ensure that care is planned around the whole family, i.e. relationship between health professionals and the family [25]. FCC involve nurse and parents interaction and caregivers-nurse relationship that results in high quality of care due to value and provision of FCC [26]. Research [27] argue for rethinking regarding FCC for children and families in hospital. By using a bioecological model of human development nurse-family partnership could be improved by community nursing, not only hospital care.

In summary, malnutrition among children in Vietnam results in growth disorders and impaired cognitive ability (underweight) and non-communicable diseases as diabetes (overweight), which influence financial consequences for the individual as well as the society. Therefore, nursing is central to prevent and/or manage malnutrition to improve health and well-being. Current study aim to describe nursing students' experiences of malnutrition among children within hospital in Vietnam.

\section{Method}

\section{Settings}

This study was conducted at Hanoi Medical University [28], one of the oldest and leading medical universities in Vietnam that strives to reach excellence in healthcare professional training, in research, and in applied science and technology. The Hanoi Medical University [28] has approximately 10,000 students registered at the university, and approximately 250 of them in the nursing program started a collaboration with Queensland University of Technology, Australia to enhance the skills of future teachers [29]. This collaboration resulted in two nursing programs, i.e., one four-year program in Vietnamese and one 4.5-year program taught in English. The advanced nursing bachelor program [30] include general education for example political ideology (22 credits), basic professional knowledge for example anatomy $(22$ credits), Professional knowledge for example community health nursing (76 credits), elective units and graduation projects (15 credits). 


\section{Design}

A qualitative method was used together with an inductive approach to understand nursing students' voices, views and thoughts regarding malnutrition among children in hospital care in Vietnam. Content analysis illustrated the use of several concepts related to the research procedures to achieve trustworthiness; credibility, dependability and transferability [31-33]. This qualitative research design is "information driven" and could be helpful when developing insightful and artful interpretations within nursing education processes [33].

\section{Data collection and participants}

A convenience small sample related to qualitative methods was used [31-33]. The inclusion criteria for participation were nursing students in their last year of education (four-year) at the bachelor's level for general nursing at the Hanoi Medical University taught in English, over the age of 18 , experience of hospital care and able to understand and speak English. An international coordinator in the Nursing Department, Hanoi Medical University sent out an inquiry, and students who were interested in participating called two of the authors ( $\mathrm{AH}$ and HF). The first seven nursing students out of 25 , were included due to limited timetable, however this small number of participants $(n=7)$ are in line with qualitative method [33]. Moreover, ethical guidelines for human and social research were considered throughout the study [34]. Data were collected in March 2018 at Hanoi Medical University, and all participants $(n=7)$ were informed regarding the aim and study procedures, and confidentiality was assured. The interviews started with background questions, including age, education and experiences in healthcare, especially hospital care, with a focus on malnutrition among children. Furthermore, data collection focused on five perspectives: Prevention of malnutrition, patient and family support, challenges in malnutrition, and the nurse's role and skills regarding malnutrition, as well as future aspects. Above interview guide (background, five open ended questions) togeth- er with the introduction question "What is the first thing that comes to mind when you hear the word malnutrition?" were translated from English to Vietnamese and were available to the participants during the interview to facilitate answers due to languages barriers. Based on the answers, related questions were asked. Moreover, examples of situations such as positive and negative aspects of hospital care regarding malnutrition among children were explored, and clarifications and further elaborations were made in English, translated in certain instances to Vietnamese by translation tools, such as Google, that translated to facilitate the interviews. Interviews estimated duration of approximately 30 minutes and were performed individually by two of the authors ( $\mathrm{AH}$ and $\mathrm{HF}$ ), and all interviews were recorded and later transcribed verbatim. All participants were female nursing students at a bachelor's level, aged between 21 to 23 years.

\section{Data analysis}

Interviews were analyzed using manifest qualitative content analysis $[31,32]$ to interpret the meaning from the content of data to address trustworthiness [33] with examples drawn from the area of nursing students' experiences with malnutrition. Written words were the basis for the analysis and the analysis was performed in the following steps (Table 1): 1 . Transcripts were read and re-read to obtain an understanding of and familiarity with the text; 2 . Meaning units (words, sentences or paragraphs) corresponding to the content areas (aim) were selected using an inductive approach (search for pattern) concerning (a) Handle family members and (b) Handle limitations; 3 . Each meaning unit were analyzed due to the aim and condensed into a description of its content and labelled with one of 81 codes; 4 . Subcategories (similarities and differences) were identified and grouped related to codes; and 5. One category was identified (overarching content): Support through family-centered care, and two subcategories (variation) were grouped: supporting healthy eating habits within the family and managing limited resources.

Table 1: Examples of analysis process.

\begin{tabular}{|c|c|c|c|c|}
\hline Meaning unit & $\begin{array}{l}\text { Condensed } \\
\text { meaning unit }\end{array}$ & Code & Subcategory & Category \\
\hline $\begin{array}{l}\text { So you cannot have a continuous taking care of a } \\
\text { patient at the same time, because of there are so } \\
\text { many patients, so many medications, you have to be } \\
\text { alert at the same time. So like one patient, you have to } \\
\text { prepare like } 15 \text { medications for this patient, and then } \\
\text { sometimes you really have to be alert because there } \\
\text { is a high risk at you making medication error if you are } \\
\text { stressed out }\end{array}$ & $\begin{array}{l}\text { Cannot take } \\
\text { care of many } \\
\text { patients at same } \\
\text { time, have to be } \\
\text { alert, high risk } \\
\text { medication error if } \\
\text { stressed }\end{array}$ & $\begin{array}{l}\text { High workload } \\
\text { Responsibility }\end{array}$ & $\begin{array}{l}\text { Supporting } \\
\text { healthy eating } \\
\text { habits }\end{array}$ & $\begin{array}{l}\text { Support through } \\
\text { family-centered } \\
\text { nursing }\end{array}$ \\
\hline $\begin{array}{l}\text { They will tell you sometimes the patient is okay, that } \\
\text { the patient has room air only, not oxygen support, but } \\
\text { actually the patient already has CODED in the ER, they } \\
\text { will conceal it. Like sometimes they endorse patients } \\
\text { and not tell you it has already twice CODED so once it } \\
\text { came here, you are not prepared, so now you have to } \\
\text { be prepared cause of the high chance of coding in your } \\
\text { area }\end{array}$ & $\begin{array}{l}\text { Sometimes } \\
\text { don't tell patient } \\
\text { already twice } \\
\text { CODED, you not } \\
\text { prepared, high } \\
\text { chance of coding } \\
\text { in your area }\end{array}$ & $\begin{array}{l}\text { Impact of } \\
\text { communication } \\
\text { Unprepared }\end{array}$ & $\begin{array}{l}\text { Managing } \\
\text { limited } \\
\text { resources }\end{array}$ & $\begin{array}{l}\text { Support through } \\
\text { family-centered } \\
\text { nursing }\end{array}$ \\
\hline
\end{tabular}


The findings are illustrated with quotes.

\section{Ethical considerations}

Ethical approval and permission for the study were obtained from the director of Nursing Department, Hanoi Medical University. No ethical approval are needed due to Swedish rules and guidelines regarding student's thesis and/or quality improvement with no estimated negative effects for potential participants $[34,35]$. Current study were performed as a bachelor thesis by nursing students at University of Gothenburg supervised by a senior researcher, therefore no ethical approval was used. However, ethical guidelines for human and social research were followed throughout the study [34]. Respect for the individual student was a primary concern during the study. All students were informed about voluntary participation, knowing their right to withdraw at any time and that their answers would be kept confidential. Moreover, the results are described in categories without identification. Respect for the participants' integrity and autonomy was thereby shown [34].

\section{Results}

Data analysis generated one category; Support through family-centered care, which includes two subcategories; Supporting healthy eating habits within the family and Managing limited resources, which describe nursing students experiences of malnutrition among children in Vietnam. Categories are presented in Figure 1.

\section{Support through family-centered care}

The category of support through family-centered care is described as facilitate healthy eating habits through cultural aspects and sustainable development in nursing. Participants described that elderly relatives as grandmas as well as traditions within the family influence what kind of meals that are served (content, nutrition). Challenges as managing limited resources at social as well as healthcare levels contribute to malnutrition among children, especially in rural areas. Therefore, nursing students stress the significant to increase financial conditions as available healthy food in public healthcare to facilitate healthy eating habits in the society. Moreover, malnutrition is not a priority area within hospital care, which contributes to limitation regarding prevent and/or managing nutrition needs among children due to hospital stay though acute care is in focus. Treatment regarding malnutrition among children is no quick fix though it is affected by different expectations among involved actors (child, family, health professionals). Therefore, participants emphasize the importance of nurse's improvement work in order to use family-centered care to support the whole family's life situation to decrease malnutrition.

\section{Supporting healthy eating habits within the family}

The subcategory of supporting healthy eating habits within the family is described as insufficient knowledge as well as cultural aspects which influence that kind of food is used and served. Nursing students highlight that relatives need available information regarding healthy eating habits due to limited knowledge regarding food in relation to nutritional facts. They emphasize variation of information channels, for example social programs from the Government to provide general information to all citizens regarding nutrition.

I think there is a lot of campaigns in Vietnam which support the children who has malnutrition. And also a lot of preventions, yeah preventions for them. (...) they give vitamins and also a lot of how to say, information

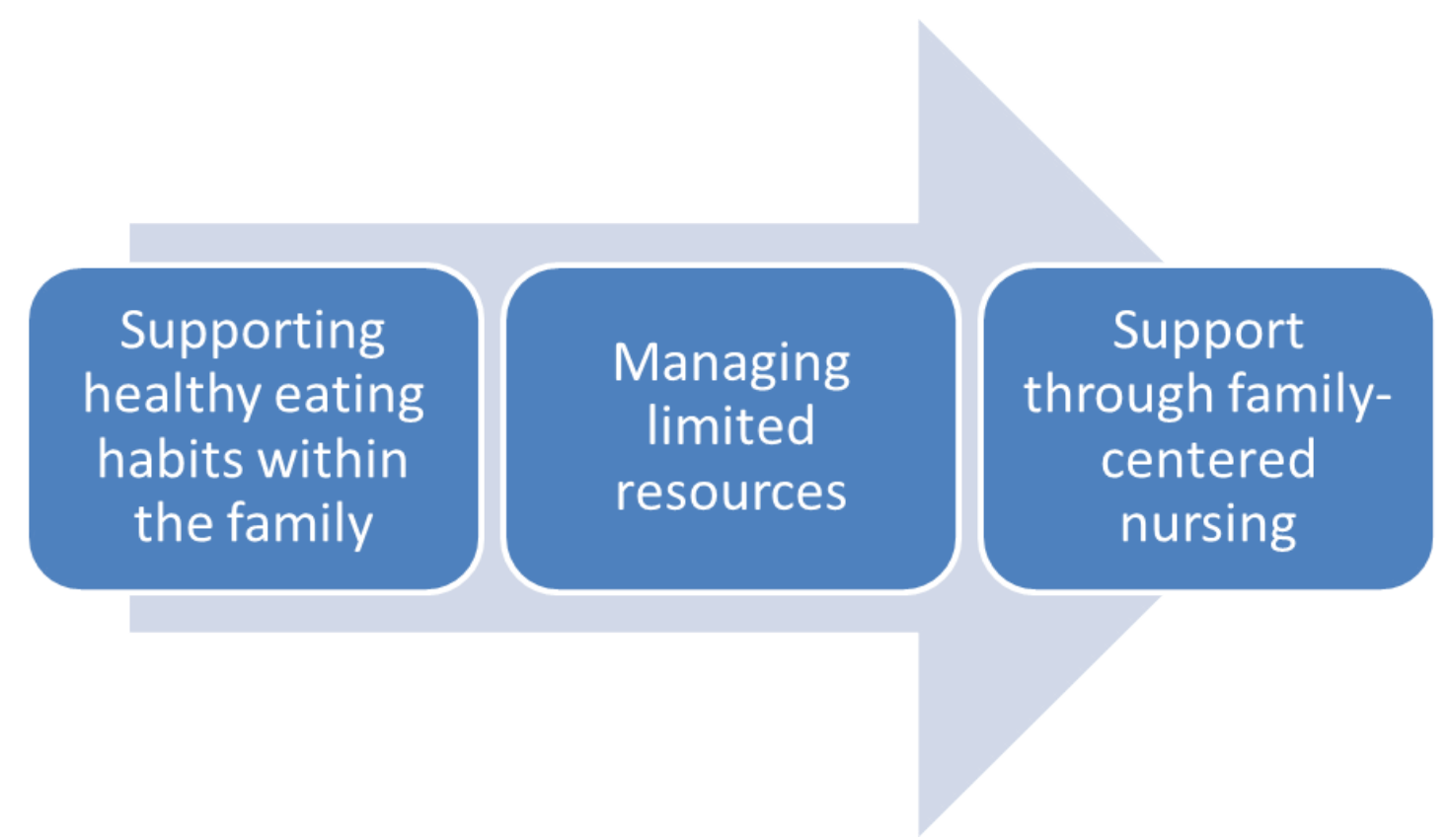

Figure 1: The categories generated in the results. 
for each family. Yes in the village we have a lot of people who take responsibility to give information for family. (Informant C)

Participants also highlight to provide children with vitamins together with education for the family with focus on parents to prevent malnutrition. Moreover, local people's knowledge (neighbors) is described as resources to support families with children at risk due to lack of nurses in the community. One nurse student describe this as:

But in Vietnam the main support is from the family members not all of the nurses or the healthcare staff because of the culture. The family, they support, they buy the food and like feed them. (Informant B)

In addition, nursing students stress that internet is a fast-growing information channel in Vietnam used for information. However, they argued that citizens need guidance how to use and judge available information regarding malnutrition (evidence-based knowledge) due to a lot of misleading information on the web. Furthermore, nursing students describe the significant of clear information regarding healthy eating habits for forthcoming mothers during pregnancy as well as during childhood. They believe that nurses preventive work regarding nutrition is missing, why improved nursing information and education is emphasized to improve nurses skills with malnutrition to be able to support families during hospital stay as well as at in their daily life at home. According to participants, nurses focusing medical aspects as difficulty in swallowing (few patients) instead of healthy nutrition for all. However, knowledgeable healthcare professionals that provide family-based care could focus on both, to prevent and cure ill health. Therefore, nursing student call for discussion and support from physicians regarding indepth communication with parents about children's nutrition needs using additional specialist knowledge (dietician).

"Most important, malnutrition children in hospital, discuss with doctors, diet. Discuss with parents how feed child, weight and height". (Informant E)

Participants emphasize that nursing is about detect children's needs, thereafter nursing is about encourage and support meal situations to facilitate healthy meals at the hospital, this could be seem as paragon when the family are admitted to their home. An example were to divide meal into smaller portions during the day, another thing was to increase the number of primary care nurses in the community to facilitate support to families that are admitted from hospital with dietary supplements.

Moreover, the meal situation is described as time-consuming when a child do not want to eat, and why nurse's support to the family is highlighted. Participants stress that nurses who facilitate play and en- couragement during meal situation create, trust during hospital stay. In addition, they consider that nurse's support increase understanding of family's daily life situation which facilitate faster recovery when nursing is adapted to the specific family's life situation. Mother's role is emphasized as significant due to the recovery part, however overwhelming health situation within the family have negative affects to children's state of health. Therefore participants highlight that nurses need to pay attention to the whole family's situation, not just the specific child that are treated at the hospital.

"The parents should care more for the human because many parents don't have time for their children, they just go work all day and leaving the children alone and they can eat everything they want". (Informant D)

Relatives are left alone at the ward to manage meal services, and due to limited knowledge regarding nutrition facts, nursing students argue that parents give children food they like without considering nutrition facts. Therefore, they emphasize the significant of dialogue with the family, to exam nutritional needs of the child to support parent's possibilities to manage basic care as meal service. Moreover, participants express that families dietary habits pass from generation to generation, why it is difficult for nurses to facilitate change to healthy eating habits with diversity of protein sources and vegetables, which results in why malnutrition and constipation is still common among children. They stress that the impact of culture in Vietnam where grandparents and other relatives provide children with food they like without reflecting on the nutritional content. Therefore, nursing students emphasizes the importance of nurse's informative and educational role to prevent malnutrition. Nurse's knowledge and skills are described as resource to decrease malnutrition within the society, i.e. improve healthy eating habits within the family by increased awareness regarding cultural aspects due to nutritious food.

"I know that some parents just do like use their experience from the past, grandparents, grandmother. Sometime it's very good but sometime it's not good and sometime it affects the children's health. So I think if we can find the problem and decide if they do right or wrong. And if wrong we can fix it". (Informant G)

\section{Managing limited resources}

The subcategory of managing limited resources is described as lack of economic conditions due to the Vietnamese population. Nursing students consider that poverty is the single most contributing factor to malnutrition among children. However, number of affected families has decreased in relation to improved living conditions with accessibility to food. On the other hand, poor families are still exposed in rural areas and cannot afford to offer enough food to their children. 
Moreover, accessibility to healthcare (clinics, hospitals) vary geographically according to large distances which limit family's tendency seeking healthcare. For children living in the countryside, hospital visits include long and risky journey, therefore children offers available resources in the nearby area and why they get use of limited competences (volunteers, friends). In addition, nursing students describe that the government provides children in vulnerable areas with vitamin A, food and/ or milk distribution. Furthermore, private companies also donate milk to children. However, participants emphasize need for improved social programs to families at risk, organized by the community.

"I cannot control, belongs to social, condition is poor, children with malnutrition very common. I want change, maybe I can't, social activities, encourage-support poor children-poor family, social program to support them". (Informant B)

Furthermore, nursing students describe that primary or community care is limited and need improvement to grow, especially in rural areas supported by mandatory national programs as free vaccinations as well as dietary supplements. According to lack of resources, national program are not fulfilled, why participants stress need for improvement. Moreover, they describe limited follow-up activities to families admitted from hospital that suffer from malnutrition, and highlight regular home visits performed by nurses to support children's health condition in their home situation.

"Because in the hospital we treat the patient and they get better and they are sent home and I do not follow them". (Informant E)

Primary and community healthcare is considered with lack of time, competence and appropriate material in relation to limited number of nurses. Working with malnutrition is described as difficult due to a various number of aspects involved. Therefore, participants argue that individualized nursing is required to provide high quality of care. They emphasize, as forthcoming nurses, need for education regarding malnutrition within the nursing programme to manage patients at risk. However, nursing students described ongoing improvement as new education programme for dietician. Moreover, participants also stress that nurses not always address nutrition-related problems (longterm processes) though emergency care always are prioritized at the hospital due to limited resources. Therefore, nursing students emphasize the importance of an overall perspective of the child and the family to be aware of risk though malnutrition cause double burden, suffering and extended hospital stays. BMI is described as a tool to detect patients at risk.

"I think the first thing is about the diet, we should set the level of the malnutrition". (Informant A)

"Because the patients are so grounded in the hospi- tal. If it's serious, so they have charge of it, but normally they don't care". (Informant A)

According to participants, malnutrition affects children's everyday life as they are physically weak with limitation to participate in daily activities as play with other children due to hospital stay. Therefore, they highlight family-based work to create conditions for treatment with less possible hospital stay using patient education to the whole family to prevent or treat malnutrition. Nursing students emphasize the importance of nurses' supportive role to the family to help them develop strategies to manage their daily living situation.

\section{Discussion}

The aim of this study was to describe nursing students' experiences of malnutrition among children in hospital in Vietnam, which were reached. Family-centered nursing [25] was considered to increase awareness regarding families at risk for malnutrition, for example families with long distances to hospital. According to Coats, et al. [36], family-centered nursing create conditions for families to take care of their children, however research showed that nurses were unsure how much efforts they should put on the family when child is patient. Nurses need knowledge regarding family-centered care as well as person-centered approaches $[25,37,38]$ to decrease malnutrition. Therefore, it is essential to focus on nursing activities that include patient education both in the community (follow up) as well as in hospital care, not only focus on emergency care and medical aspects. In addition, nurse's ethical dimension due to nursing, for example blame parents for being ill negatively influence quality of care, why education regarding malnutrition is needed to understand nutrition needs [39]. Improved education [40] for nurses caring for children with malnutrition ensure that caring is planned to include all family members [25]. Teaching that are implemented throughout nursing education provide knowledge and awareness to forthcoming nurses to identify families at risk, which decrease suffering as well as improve treatment of malnutrition due to manage limited resources (family, community, hospital). Nurses who focus patient education regarding nutrition facts and healthy eating habits through family-centered approach could facilitate health and well-being [21].

Support regarding healthy nutrition is addressed by Kieckhefer, et al. [41] who found that education program increase family's ability to manage their daily living situation, i.e. to care for their children. Based on above research, further development regarding education programs (by standardized guidelines) at national level is needed, such as information [15] given by nurses (primary health care, hospital care) before and after giving birth regarding nutrition facts. According to family members responsibility for children's meals during hospital stay in Vietnam, improved knowledge 
regarding nutrition due to recovery is needed [42]. Nurse's limited possibilities to influence patient's food intact in Vietnamese hospital contribute to frustration and dissatisfaction among staff. Therefore, nursing is about patient education to improve healthy eating habits for families regardless of time and place (home, hospital). By using family-centered nursing approach [25], nurses get familiar with eating habits, important information to support the whole family regarding meal service and nutrition facts due to that suffering are expressed in different ways $[36,43]$. By using simple language that are understandable for the family results in increased knowledge and confidence regarding malnutrition $[10,39]$.

Patient education regarding nutrition and malnutrition increase families awareness of dietary habits which improve knowledge and skills within the family [10]. Families eating habits are described as based on cultural heritages, not adapted to children's nutritional needs [44] which results in limit health and well-being though traditional Vietnam diet (rice, meat), especially with poor families, is limited due to healthy nutritional content [15]. Therefore, James [44] stress that family and friends need to be supported when it comes to changes, i.e. abandon cultural heritage within the family. By supportive nurses, shown in a study from Ghana [43] elderly relatives influence on traditional eating habits in Vietnam could be handled. Otherwise, mistrust regarding healthcare professionals knowledge within malnutrition results in lack of compliance to nurse's counselling though parents follow senior family members' advice instead of healthcare providers. Mutual relationship [37] built through a family-centered approach [25] can alleviate future suffering. One key point is trust between health professionals and the child's mother, and why regular contact with nearby and available healthcare is significant before visiting hospital with problems as malnutrition [43]. Evidencebased information from a well-skilled nurse improve high quality of health [45] by developing confidence and trust using person-centeredness between family and healthcare providers [38]. Nurses who are aware of cultural impact are better prepared to support families to change their eating habits.

Moreover, economic constraints in healthcare cause consequences for the individual as well as the society. Poor families with a lot of children as well as limited available healthcare (rural areas), increase risk of extensive illness, including malnutrition that are difficult to treat [42]. Another contributing factor is shortage of nurses, and why patient-nurse ratio in relation to working hours spent in hospital or clinics is too high. Therefore, nurses are always forced to prioritize emergency care, not malnutrition which results in longer hospital stays as well as prolonged treatments [8]. This cause increase economic difficulties as well as suffering, i.e. double burden [15]. Hospital care deals with critically ill children $[10,46]$, however recovery is delayed by limited nutrition and why nursing tasks is significant during hospital stay. Lack of nursing cause suffering for patients and their families as well as frustration among nurses. By preventive activities and early identification of ill health as malnutrition among the population detected by nurses in hospital as well as within the community improved health among children and their families. According to limited number of nurses, improvement is needed (increased number of nurses) to improve quality of care though malnutrition is complex with need of professional support to affected children and their family.

\section{Limitations}

A limitation of this study is that it was conducted at one nursing programme in one country, Vietnam. The small sample limits the ability to generalize to other settings. However, the trustworthiness of the results was ensured through a scientific systematic analysis using manifest qualitative content analysis, a well-documented methodology [31,32]. The study's validity, however, might be debated due to the data collection procedure, which involved a limited number of interviews $(n=7)$. The variations in the nursing student's experiences of malnutrition among children and their English skills could also be a limitation [47]. Moreover, the Vietnam differs in its social structure, education and healthcare systems, which must be taken into consideration with regard to the transferability of the current study. Further studies are needed to develop knowledge regarding malnutrition among children in Vietnam. For example, quantitative research that includes a larger number of informants could contribute to increased knowledge regarding malnutrition among children.

\section{Conclusion}

Health professionals as nurses play a central role in preventing, detecting and early treatment of children with malnutrition. Educating and supporting families through a family-centered approach facilitate improved health by identifying risk factors such as financial vulnerability, eating habits and access to healthcare. Nurses could improve high quality of care in countries as Vietnam, however this requires improvements regarding nursing education (malnutrition, family-centered care) as well as focus on nursing tasks (prevention, followup) in primary and hospital care by increased number of nurses.

\section{Ethical Approval}

Ethical approval was not required for this study.

\section{Contributions}

Study design: $A H, H F, K R$; Data collection: $A H, H F$; Data analysis: AH, HF, KR; Manuscript preparation: KR. 


\section{Sources of Funding}

The authors received no financial support for this research for authorship and/or publication of this article.

\section{Acknowledgements}

We thank nursing students at the Hanoi Medical University who participated in the study and the University of Gothenburg Centre for Person-Centered Care (GPCC), Sahlgrenska Academy, University of Gothenburg, Sweden.

\section{Conflicts of Interest}

The authors declared no conflicts of interest with respect to the authorship and/or publication of this article.

\section{References}

1. World Health Organization (2016) What is malnutrition?

2. United Nations (2015) Millennium development goals and beyond 2015 .

3. UNICEF, World Health Organization, World Bank Group (2017) Levels and trends in child malnutrition.

4. World Bank (2017) Prevalence of stunting, height for age (\% of children under 5 ).

5. Huong PT, Lam NT, Thu NN, Quyen TC, Lien DT, et al. (2014) Prevalence of malnutrition in patients admitted to a major urban tertiary care hospital in Hanoi, Vietnam. Asia Pac J Clin Nutr 23: 437-444.

6. Truong Quang Dat, Le Nguyen Huong Giang, Nguyen Thi Tuong Loan, Vo Van Toan (2018) The prevalence of malnutrition based on anthropometry among primary schoolchildren in Binh Dinh province, Vietnam in 2016. AIMS Public Health 5: 203-216.

7. https://data.unicef.org/topic/nutrition/malnutrition/\#

8. Martins VJ, Toledo Florêncio TM, Grillo LP, Franco M do CP, Martins PA, et al. (2011) Long-Lasting effects of undernutrition. Int $\mathrm{J}$ Environ Res Public Health 8: 18171846.

9. Said-Mohamed R, Pettifor JM, Norris SA (2018) Life History theory hypotheses on child growth: Potential implications for short and long-term child growth, development and health. Am J Phys Anthropol 165: 4-19.

10. Jefferies D, Johnson M, Ravens J (2011) Nurturing and nourishing: The nurses' role in nutritional care. J Clin Nurs 20: $317-330$.

11. Green SM, James EP, Latter S, Sutcliffe M, Fader MJ (2014) Barriers and facilitators to screening for malnutrition by community nurses: A qualitative study. J Hum Nutr Diet 27: 88-95.

12. Lindegaard Pederson J, Pedersen PU, Damsgaard EM (2017) Nutritional follow-up after discharge prevents readmission to hospital - A randomized clinical trial. J Nutr Health Aging 21: 75-82.

13. World Health Organization (2018) Body mass index - BMI.

14. National Health Service (2018) Children's BMI.

15. World Health Organization (2018) Why does childhood overweight and obesity matter?
16. European Parliament (2014) The social and economic consequences of malnutrition in ACP countries.

17. Thang NM, Popkin B (2003) Child malnutrition in Vietnam and its transition in an era of economic growth. J Hum Nutr Diet 16: 233-244.

18. Le Nguyen BK, Le Thi H, Nguyen Do VA, Tran Thuy N, Nguyen Huu C, et al. (2013) Double burden of undernutrition and overnutrition in Vietnam in 2011: Results of the SEANUTS study in 0.5-11-year-old children. Br J Nutr 110: 45-56.

19. Kien VD, Lee HY, Nam YS, Oh J, Giang KB, et al. (2016) Trends in socioeconomic inequalities in child malnutrition in Vietnam: Findings from the multiple indicator cluster surveys, 2000-2011. Glob Health Action 9: 29263.

20. Hien N, Hoa (2009) Nutritional status and determinants of malnutrition in children under three years of age in Nghean, Vietnam. Pakistan Journal of Nutrition 8: 958-964.

21. International Council of Nurses (2012) The ICN Code of Ethics for Nurses.

22. Nordman T, Santavirta N, Eriksson K (2008) Developing an instrument to evaluate suffering related to care. Scandinavian Journal of Caring Sciences 22: 608-615.

23. Kortesluoma RL, Punamäki RL, Nikkonen M (2008) Hospitalized children drawing their pain: The contents and cognitive and emotional characteristics of pain drawings. $J$ Child Health Care 12: 284-300.

24. Eifried S (2003) Bearing witness to suffering: The lived experience of nursing students. J Nurs Educ 42: 59-67.

25. Shields $L$ (2015) What is "family-centered care"? European Journal for Person Centered Healthcare 3: 139-144.

26. Harrison TM (2010) Family centered pediatric nursing care: State of the Science. J Pediatr Nurs 25: 335-343.

27. Tallon MM, Kendall GE, Snider PD (2015) Rethinking family-centred care for child and family in hospital. J Clin Nurs 24: 1426-1435.

28. Hanoi Medical University (2018) History of Hanoi Medical University.

29. Harvey T, Calleja P, Thi DP (2013) Improving access to quality clinical nurse teaching - a partnership between Australia and Vietnam. Nurse Educ Today 33: 671-676.

30. Hanoi Medical University (2018) Training capacity of Hanoi Medical University.

31. Graneheim UH, Lundman B (2004) Qualitative content analysis in nursing research: Concepts, procedures and measures to achieve trustworthiness. Nurse Educ Today 24: 105-112.

32. Graneheim UH, Lindgren BM, Lundman B (2017) Methodological challenges in qualitative content analysis: A discussion paper. Nurse Educ Today 56: 29-34.

33. Polit D, Beck CT (2017) Nursing research: Generating and assessing evidence for nursing practice. Wolters Kluwer Health/Lippincott Williams and Wilkins, Philadelphia.

34. Codex (2018) Rules and guidelines for research. The humanities and social sciences.

35. Health and Medical Care Act (2017:30).

36. Coats H, Bourget E, Starks H, Lindhorst T, Saiki-Craighill S, et al. (2018) Nurses' reflections on benefits and challenges of implementing family-centered care in pediatric intensive care units. Am J Crit Care 27: 52-58. 
37. Ekman I, Swedberg K, Taft C, Lindseth A, Norberg A, et al. (2011) Person-centered care-ready for prime time. Eur J Cardiovasc Nurs 10: 248-251.

38. Ricoeur P (1992) Oneself as another. University press, Chicago.

39. Puoane T, Sanders D, Ashworth A, Ngumbela M (2006) Training nurses to save lives of malnourished children. Curationis 29: 73-78.

40. Vasli P, Dehghan-Nayeri N, Borim-Nezhad L, Vedadhir A (2015) Dominance of paternalism in family-centered care in the pediatric intensive care unit (PICU): An ethnographic study. Issues Compr Pediatr Nurs 38: 118-135.

41. Kieckhefer G, Trahms M, Churchill SS, Kratz S, Uding $S$, et al. (2014) A randomized clinical trial of the building on family strengths program: An education program for parents of children with chronic health conditions. Matern Child Health J 18: 563-574.

42. Bernhed J, Mollstedt M, Rosengren K (2018) Dare to care - A qualitative content analysis regarding nursing students view on HIV in Vietnam. Home Health Care Management \& Practice 30: 187-194.
43. Ackatia-Armah NM, Addy NA, Ghosh S, Dubé L (2016) Fostering reflective trust between mothers and community health nurses to improve the effectiveness of health and nutrition efforts: An ethnographic study in Ghana, West Africa. Social Science \& Medicine 158: 96-104.

44. James DC (2004) Factors influencing food choices, dietary intake, and nutrition-related attitudes among African Americans: Application of a culturally sensitive model. Ethn Health 9: 349-367.

45. Blackman IR, Giles TM (2017) Can nursing students practice what is preached? Factors impacting graduating Nurses' abilities and achievement to apply evidence-based practices. Worldviews Evid Based Nurs 14: 108-117.

46. Arvidsson E, André M, Borgquist L, Andersson D, Carlsson $P(2012)$ Setting priorities in primary health care - on whose conditions? A questionnaire study. BMC Fam Pract 13: 114.

47. Squires $A$ (2008) Language barriers and qualitative nursing research: Methodological considerations. Int Nurs Rev 55: 265-273. 